\title{
The realms of possibility
}

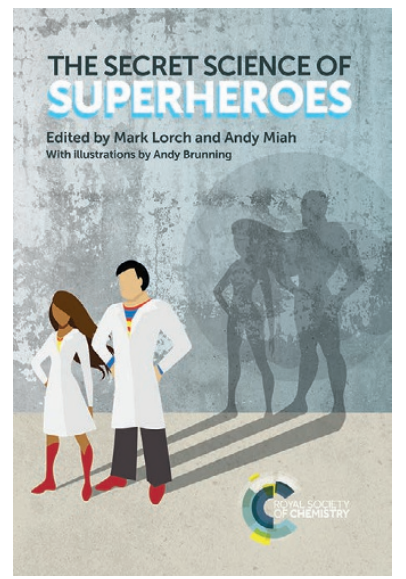

The Secret Science of Superheroes Edited by Mark Lorch and Andy Miah Royal Society of Chemistry, 2017, 227pp., £19.99

$\mathrm{n}$ worlds where superheroes exist, I often imagine how such powers could be possible.

These are worlds in which we often have to suspend belief. But what if we didn't?

The authors - a banded 'super' team of scientists - of The Secret Science of Superheroes aim to explore the many scientific principles underpinning the superpowers we marvel at.

This book is composed of short, concise chapters that delve into individual superpowers and provide examples of comparable abilities exercised in the world we live in, whether they appear in nature or spawn from technology. The reader is challenged to consider what sort of nutritional intake Spider-Man would need to kickstart his crime-fighting day, or how the ins and outs of Batman's suit allow him to keep Gotham City safe.

Cover-to-cover, the book is short and sweet, an experience populated with quintessential superheroes and comic history (the authors' knowledge is impressive). It introduces a wide range of topics that can captivate a diverse range of readers - from those with general science knowledge to comic book and film enthusiasts.
Each chapter is structured similarly and is accompanied by educational illustrations by Andy Brunning, providing the perfect blend of entertaining and informative material with plenty of references for the reader to peruse should he or she want to explore the science a little more. The sheer diversity of the content means that not all chapters may appeal to you. However, I would dissuade against skipping them. On first glance of the contents page, I had an opinion on what chapters I thought I would enjoy the most. How wrong I was; do not judge a chapter by its title. A highlight of the book included an exploration into how Wonder Woman's Lasso of Truth could be made from aramid rope - a type of material made from Kevlar - with an absorbent layer that allows a truth serum drug, such as sodium pentothal, to permeate the skin of the captive.

What I enjoyed most about this book was how well it made difficult concepts understandable. For example, one chapter focuses on the Hulk and his transformation from Bruce Banner as a model to explain the biological processes of cancer. These types of discussions - based on our present

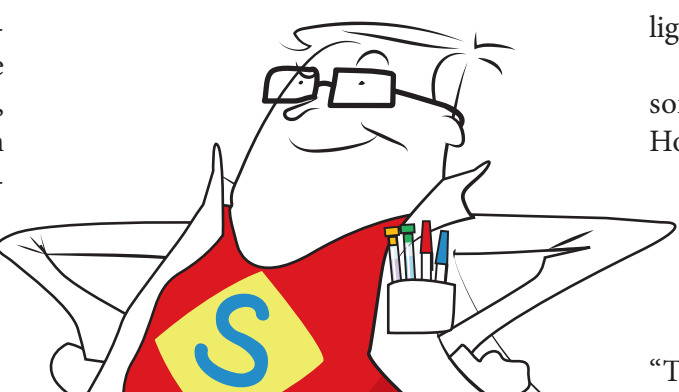

understanding of disciplines such as genetics, materials science and physics, among others could inspire those interested in comic books and films to take up the study of science. Superheroes such as Batman and Iron Man were my exposure and gateway into science; these characters made science cool, and this is exactly what this book does.

\section{\& What I enjoyed most} about this book was how well it made difficult concepts understandable

It is hard to read this book and not wonder what ability I would want. I often overlook the adverse effects and the dark side of power. This book explores these trade-offs and made me rethink what power I would want - remember, with great power comes great responsibility.

Those with a keener hawkeye will notice a few mistakes, but these can be forgiven. After all, the authors embraced the power of The Flash and wrote this book in just 36 hours. This book does what it sets out to do: it introduces a wide range of scientific concepts in a fun, light-hearted and understandable tone.

Occasionally, we have to accept that, sometimes, superpowers are just magic. However, the world as we know it may be working towards 'super', with advancements in technology and the development of military supersuits, memory materials and programmable polymers. As one of the authors states,

"The science behind superheroes is not entirely outside the realms of the physical possibilities that operate within our world." Science is a marvellous field that might just make the impossible possible.

Reviewed by Cam Mezé
Caio Bracey/

Macmillan Publishers Limited 038/s41570-017-0089

doi: $\frac{10.1038 / 541570-017-0089}{\text { Published online } 18 \text { Oct } 2017}$ 